\title{
Physical activity as a protective factor against development of liver steatosis in patients infected with hepatitis C
}

\author{
Lucas de Lucena Simões e Silva ${ }^{1}$, Matheus Santos de Souza Fernandes ${ }^{1}$, Eline Autran de Lima ${ }^{1}$ \\ Raul Emídio de Lima², Patrícia Muniz Mendes Freire de Moura ${ }^{3}$
}

${ }^{1}$ School of Physical Education, University of Pernambuco, Recife, Pernambuco, Brazil; 2 Aggeu Magalhães Institute/ IAM-FIOCRUZ-PE, Brazil; ${ }^{3}$ Pernambuco Liver Institute, Recife, Pernambuco, Brazil

\section{Summary}

Study aim: Was to verify whether the regular practice of physical activity promotes some protective factor against the development of LS in patients infected with hepatitis C virus (HCV).

Materials and method: Clinical data were obtained through medical records available at the Pernambuco Liver Institute. Physical activity levels were obtained through the International Physical Activity Questionnaire (IPAQ) short form to classify the patients according to the guidelines of the American College of Sports Medicine (ACSM).

Results: The sample consisted of patients of both genders, over 18 years of age, who had positive anti-HCV, HCV-RNA and confirmatory tests for presence or absence of liver steatosis. 126 patients were included in the study. Patients with liver steatosis (G1) were more frequently male (57\%) compared to patients without liver steatosis $(\mathrm{G} 2)(\mathrm{p}=0.02)$. Physical activity analysis showed significant differences for GGT ( $p=0.04)$, HDL $(p=0.04), \operatorname{AF}(p=0.02)$, viral genotype $3(p=0.04)$ and waist-to-hip ratio $(p=0.01)$ in anthropometric data. Correlation analysis showed a significant difference for GGT $(r=-0.23 ; p=0.01)$ and total bilirubin (BT) $(\mathrm{r}=-0.22 ; \mathrm{p}=0.01)$.

Conclusions: Regular practice of physical activity generates a protective factor against the development of LS in patients infected by the hepatitis $\mathrm{C}$ virus and it is associated with the maintenance of variables related to hepatic and biochemical damage in patients infected with $\mathrm{HCV}$.

Key words: Physical activity - Hepatitis C - Fatty liver - Hepatology - Health

\section{Introduction}

Liver steatosis (LS) is characterized by the excessive accumulation of lipids in the liver. Under histopathological conditions, this excessive rate represents more than $5 \%$ of the organ weight [25]. This condition promotes hepatic damage and comprises a large spectrum of pathological conditions with high evolutionary potential for other chronic hepatic disorders, including cirrhosis and hepatocellular carcinoma (HCC) [25].

As the main factor for its development, the lifestyle can contribute to the worsening or regression of the disease [12]. Physical inactivity, high fat diet, type of work, leisure activity options and form of locomotion are determinant factors for the development and/or worsening of LS. These factors lead to a reduction in the occupational physiological demand, which in general presents low energy expenditure [22]. In addition, studies indicate that the vast majority of people with LS have some of the components of the metabolic syndrome, which is another risk factor in the life quality of patients [22, 24].

In recent years the relation of regular and systematic physical activity with health-related processes has been discussed and widely analyzed, especially with regard to its impact on quality of life. It is currently understood that lifestyle affects the quality of life or, in the worst case, the onset of various morbidities [16, 24]. In addition, physical inactivity is associated with low levels of cardiorespiratory capacity and a high prevalence of obesity [2].

A healthy lifestyle is associated with an increase in the practice of physical activities, which can be performed at work, in the form of locomotion, leisure and domestic activities. Studies have shown that physical activity generates beneficial effects on health $[5,9,19]$. However, many people still have low levels of physical activity [10]. 
Although there are advances in technology and science, the relation between the regular practice of physical activity and clinical status of patients with HCV remains unknown. LS has a strong dependence on lifestyle, and understanding how regular practice of physical activities can modulate healthy behavior is relevant for health promotion programs. In addition, these patients have a double impairment due to hepatic damage caused by viral infection and the excessive fat deposition in the liver. The objective of the study was to verify whether the regular practice of physical activity promotes some protective factor against the development of LS in patients infected with HCV.

\section{Materials ans method}

Sample: The sample consisted of patients of both genders, over 18 years of age, infected by the hepatitis $\mathrm{C}$ virus, who attended the Institute of Liver and Transplants of Pernambuco (IFP). Subjects included had positive anti-HCV,
HCV-RNA reagent and had signed the Informed Consent Form. The diagnosis for liver steatosis was performed by liver biopsy. Subjects with co-infection such as HBV, HIV, HTLV, alcohol consumption or those who did not clearly report daily physical activities were excluded.

Study groups: The patients assigned to groups with liver steatosis (G1) or without (G2). After obtaining the results on physical activity, groups G1 and G2 were subdivided into physically active and physically inactive patients.

Physical activity and clinical data: Clinical data were obtained through medical records available at the IFP. Physical activity levels were obtained through the International Physical Activity Questionnaire (IPAQ) short form to classify the patients as physically active or inactive according to the guidelines of the American College of Sports Medicine (ACSM) [10]. This questionnaire classifies physical activ ity based on the frequency, intensity and duration of the exercise, and is divided into three categories: moderate activity, high activity, insufficient activity.

Table 1. Characteristics of the study population, according to the presence and absence groups of liver steatosis and physical activity levels

\begin{tabular}{|c|c|c|c|c|c|c|}
\hline & \multicolumn{2}{|c|}{ Liver steatosis $(\mathrm{G} 1)(\mathrm{n}=72)$} & \multicolumn{2}{|c|}{ No liver steatosis $(\mathrm{G} 2)(\mathrm{n}=54)$} & \multirow{2}{*}{$\mathrm{p}$} & \multirow{2}{*}{$\mathrm{p}^{*}$} \\
\hline & Active $(n=63)$ & Inactive $(\mathrm{n}=9)$ & Active $(\mathrm{n}=38)$ & Inactive $(\mathrm{n}=16)$ & & \\
\hline \multicolumn{7}{|l|}{ Clinical } \\
\hline Age [years] & $55.3 \pm 10$ & $52.9 \pm 10$ & $53.4 \pm 9.6$ & $59.4 \pm 12.6$ & 0.70 & 0.35 \\
\hline DM & $14.3 \%$ & $22.2 \%$ & $7.9 \%$ & $13.3 \%$ & 0.42 & 0.59 \\
\hline HAS & $46 \%$ & $66.7 \%$ & $47.4 \%$ & $53.4 \%$ & 0.45 & 0.36 \\
\hline Male Gender & $35 \%$ & $22.2 \%$ & $47.7 \%$ & $66.7 \%$ & 0.02 & 0.26 \\
\hline \multicolumn{7}{|l|}{ Laboratory data } \\
\hline $\mathrm{AST}[\mathrm{U} / \mathrm{L}]$ & $49(16-327)$ & $53(22-268)$ & $39(17-228)$ & $71(28-144)$ & 0.09 & 0.14 \\
\hline $\operatorname{ALT}[\mathrm{U} / \mathrm{L}]$ & $69(07-487)$ & $75(25-452)$ & $46(19-295)$ & $63(36-293)$ & 0.08 & 0.16 \\
\hline GGT [U/L] & $79(10-640)$ & $60(3-378)$ & $63(15-334)$ & $133(44-198)$ & 0.90 & 0.04 \\
\hline $\mathrm{HDL}[\mathrm{mg} / \mathrm{dL}]$ & $44(21-106)$ & $52(37-73)$ & $53(28-82)$ & $38(21-63)$ & 0.50 & 0.04 \\
\hline $\mathrm{LDL}[\mathrm{mg} / \mathrm{dL}]$ & $96.6 \pm 28.3$ & $98.5 \pm 39.3$ & $99.8 \pm 41.7$ & $94.3 \pm 30.1$ & 0.96 & 0.60 \\
\hline $\mathrm{TG}[\mathrm{mg} / \mathrm{dL}]$ & $103(47-356)$ & $100(54-231)$ & $111(42-187)$ & $110(77-149)$ & 0.34 & 0.95 \\
\hline $\mathrm{TC}[\mathrm{mg} / \mathrm{dL}]$ & $161 \pm 35$ & $171 \pm 34$ & $178 \pm 40$ & $156 \pm 31$ & 0.34 & 0.88 \\
\hline $\mathrm{AP}[\mathrm{U} / \mathrm{L}]$ & $78(12-363)$ & $75(45-223)$ & $66(46-213)$ & $100(51-263)$ & 1.00 & 0.02 \\
\hline $\mathrm{AFP}[\mathrm{U} / \mathrm{L}]$ & $4.3(0.6-39)$ & $4.0(1.5-9.2)$ & $3.8(1.3-29)$ & $3.5(1.2-22)$ & 0.40 & 0.89 \\
\hline $\mathrm{TB}[\mathrm{U} / \mathrm{L}]$ & $0.6(0.1-3.8)$ & $0.7(0.1-1.3)$ & $0.6(0.2-2.0)$ & $0.7(0.3-2.9)$ & 0.60 & 0.17 \\
\hline Viral Gen. 3 & $20.8 \%$ & $5.5 \%$ & $14.8 \%$ & $9.2 \%$ & 0.54 & 0.04 \\
\hline
\end{tabular}

$p=$ comparison between liver steatosis and no liver steatosis; $p^{*}=$ comparison between physical activity levels; DM= diabetes mellitus; HAS = hypertension; AST = aspartate aminotransferase; ALT = alanine aminotransferase; GGT = gamma glutamyltranspeptidase; HDL = high-density lipids; LDL = low-density lipids; $\mathrm{TG}=$ triglycerides; $\mathrm{TC}=$ total cholesterol; $\mathrm{AP}=$ alkaline phosphatase; $\mathrm{AFP}=$ alpha-protein; $\mathrm{BT}=$ total bilirubin; Viral Gen 3 = viral genotype 3; values in parentheses represent the group's minimum and maximum values respectively; $\boldsymbol{p}<\mathbf{0 . 0 5}$. 
Table 2. Anthropometric data found in the study population, according to physical activity levels and presence of hepatic steatosis

\begin{tabular}{lcccccc}
\hline & \multicolumn{2}{c}{ Liver steatosis $(\mathrm{n}=72)$} & \multicolumn{2}{c}{ No liver steatosis $(\mathrm{n}=54)$} & $\mathrm{P}$ & $\mathrm{p}^{*}$ \\
\hline Abd. Circ. & $96.1 \pm 10.3$ & $95.7 \pm 9.8$ & $94.4 \pm 12$ & $99.6 \pm 14.1$ & 0.83 & 0.37 \\
BMI & $26.7 \pm 4.6$ & $27 \pm 4.2$ & $25.6 \pm 4.2$ & $24.4 \pm 3.3$ & 0.08 & 0.38 \\
WHR & $0.58 \pm 0.07$ & $0.57 \pm 0.06$ & $0.57 \pm 0.08$ & $0.59 \pm 0.09$ & 0.49 & 0.60 \\
WHR* & $0.91 \pm 0.08$ & $0.95 \pm 0.12$ & $0.93 \pm 0.12$ & $0.99 \pm 0.10$ & 0.06 & $\mathbf{0 . 0 1}$ \\
\hline
\end{tabular}

Abd. Circ. $=$ abdominal circumference; $\mathrm{BMI}=$ body mass index; $\mathrm{WHR}=$ waist-to-height ratio; $\mathrm{WHR} *=$ waist-to-hip ratio; $p=$ comparison between liver steatosis groups; $p^{*}=$ comparison between physical activity levels; $\boldsymbol{p}<\mathbf{0 . 0 5}$.

The group considered as "physically active" consisted of patients classified as having moderate and/or high activity and the "physically inactive" group consisted of those who were considered as having insufficient physical activity. In addition, IPAQ shows validity and reproducibility for the Brazilian population [13]. The study was approved by the Ethics Committee with the CAAE: 48823015.3.0000.5192, according to resolution $466 / 12$ of studies with human beings. This study followed the standards set by the national health council for human research.

Statistical analysis: The data are given as means \pm SD (standard deviation) when parametric and median (minimum-maximum) when non-parametric. The ShapiroWilk test was used to check the normal distribution. The comparison between groups was carried out using MannWhitney test if the data were not normally distributed and the $t$-test for normal distribution. For correlation analysis between time spent in physical activity per week and liver enzymes we used the Spearman or Pearson test according to the normality test. In the multivariate analysis, the results are presented using the odds ratio (OR) with a 95\% confidence interval $(\mathrm{CI})$ to indicate possible risk associations. Odds ratios were adjusted according to the possible confounding variables through multivariate logistic regression. The software GraphPad Prism v 5.0 was used for all statistics.

\section{Results}

126 patients were included in the study. The group with LS (G1) had a higher frequency of males (57\%) compared to $\mathrm{G} 2(\mathrm{p}=0.02)$. After obtaining the results on physical activity, groups G1 and G2 were subdivided into physically active and physically inactive patients. In the physical activity analysis, significant difference were found for GGT $(p=0.04)$, HDL $(p=0.04)$, alkaline phosphatase
(AP) $(p=0.02)$ and viral genotype $3(p=0.04)$. No other significant values were found in this analysis. Table 1 shows the data referring to the characterization of the study population.

Anthropometric data showed a significant difference only for waist-to-hip ratio in comparison of physical activity levels $(p=0.01)$ (Table 2$)$. For other variables, no significant differences were found.

Multivariate regression analysis showed a significant difference only for the level of physical activity $(\mathrm{p}=0.04)$. For other variables analyzed, no significant differences were observed (Table 3).

Regarding the laboratory variables, in the correlation analyses, there was a significant difference for GGT $(p=0.01)$ and total bilirubin (BT) $(p=0.01)$. A correlation of physical activity and GGT $(\mathrm{r}=-0.23)$ and BT $(r=-0.22)$ was observed through the Spearman test. For the other liver enzymes, there were no significant differences. Figure 1 shows the correlation degree and statistical difference, respectively.

Table 3. Multivariate logistic regression analysis for predictive factors of liver steatosis development in patients with $\mathrm{HCV}$

\begin{tabular}{lcc}
\hline & OR $(95 \%$ IC) & P \\
\hline Sex & $0.47(0.20-1.07)$ & 0.07 \\
GGT & $1.10(0.49-2.48)$ & 0.80 \\
AP & $1.06(0.47-2.37)$ & 0.88 \\
Viral Gen. 3 & $1.16(0.75-1.79)$ & 0.48 \\
Waist-to-hip ratio & $0.55(0.24-1.22)$ & 0.14 \\
Physical activity levels & $0.34(0.12-0.97)$ & $\mathbf{0 . 0 4}$ \\
\hline
\end{tabular}

GGT = gamma glutamyltranspeptidase; $\mathrm{AP}=$ alkaline phosphatase; $\mathrm{Vi}-$ ral Gen. 3 = viral genotype $3 ; \boldsymbol{p}<\mathbf{0 . 0 5}$ 

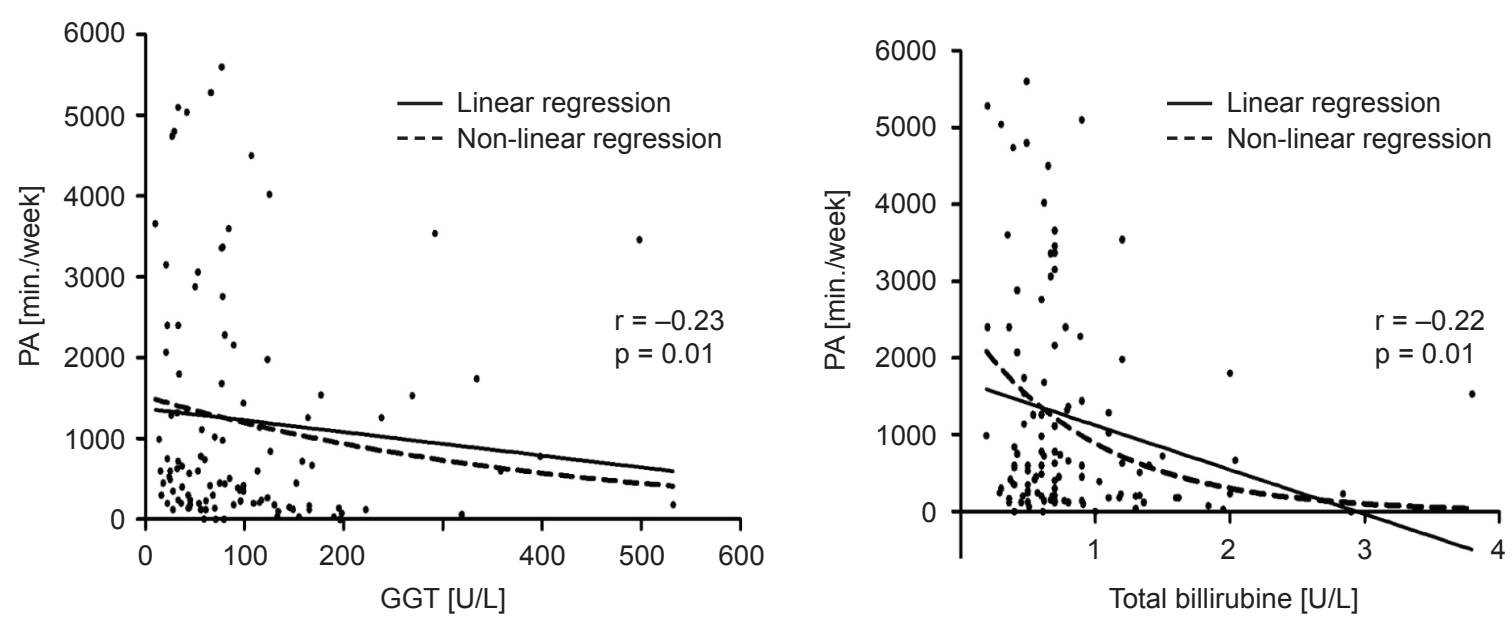

Fig. 1. Correlation analysis between laboratory variables and time spent in physical activity per week of study population. GGT = gamma-glutamyl transferase; PA = time spent in physical activity per week

\section{Discussion}

The modern lifestyle characterized by a high-fat diet and low levels of physical activity are factors that contribute to the growing number of people with LS, regardless of socioeconomic conditions. Due to its association with metabolic syndromes and increased cardiovascular risk, LS causes concerns about public health, especially when associated with these factors. In addition, it has an evolutionary potential for chronic liver diseases such as cirrhosis and hepatocellular carcinoma, which is the main cause of liver transplant [25].

In the present study, it was observed that patients with LS were mostly infected with viral genotype 3 . The literature indicates that the average prevalence of LS in patients with hepatitis $\mathrm{C}$ is $55 \%$ and may vary according to the different viral genotypes [1]. In addition, the presence of genotype 3 is associated with the presence and development of LS in such patients [3]. Regarding the laboratory variables that assess liver damage, significant differences were found only for gamma-glutamyltranspeptidase (GGT) and AP. The plasma level of GGT, associated with low levels of physical activity, has been reported as one of the predictors of diabetes [18]. Some studies show that the regular practice of physical activity can regulate the values of this transaminase [19,20]. Alkaline phosphatase is used in clinical practice to check for possible hepatic damage, but this is more related to the onset and development of osteoarticular diseases [24]. In our study, the physically active patients maintained lower values of this enzyme in relation to the group of inactive patients. It was not possible to correlate alkaline phosphatase values in patients with osteoarticular diseases, since this number of patients was not representative in our study population. Although no significant differences were found for hepatic transaminases
(AST, ALT), we believe that in our study the patients belonging to this group managed to maintain a homogeneous standard in relation to the transaminase values. In addition, it is possible to affirm that the regular practice of physical activity was able to reduce the virological aggression of these patients. However, more studies related to physical activity and virological activity in patients with $\mathrm{HCV}$ are required to confirm this hypothesis.

The study also found a negative correlation between GGT levels and time spent in physical activity, reflecting that regular practice of physical activity can beneficially influence the serum levels of this enzyme in patients with LS [19]. It is important to emphasize that regular practice of systematized physical activities may also reduce AST and ALT levels, generating a beneficial picture in such individuals. However, no significant results were found for these variables in our study. One possible explanation for this is the exposure of patients to the hepatitis $\mathrm{C}$ virus, which in turn generates liver damage regardless of the lifestyle adopted by the individual. In addition, the sample size may have been a limiting factor in finding such differences.

In the correlation analyses, a significant negative correlation was found between total serum bilirubin levels and time spent in physical activity. The total bilirubin concentration is one of the parameters used in the evaluation of liver function, in which values above normal may suggest disturbances in viscera functioning and/or hepatic parenchyma lesions [18]. It is plausible that the practice of physical activity acts as a regulatory factor beneficial to the population evaluated.

The lipid profile showed a significant difference only for HDL in comparison to physical activity levels. This lipoprotein has been reported as a protective factor against cardiovascular diseases, due to its activity of removal of atheroma plaques. Currently the literature indicates that regular practice of physical activity can increase and 
maintain the values of this lipoprotein [8]. In our study, the physically active patients demonstrated higher HDL values. Our results were similar to the findings of other studies [23 6]. Our findings were similar to those of Franco et al. [7]. It has been shown that lifestyle modifications (eating habits, physical activity) and variables linked to training such as intensity, duration and frequency may influence cholesterol modulations and biochemical profile.

The waist-to-hip ratio is an anthropometric index used to verify the presence of fat in the abdominal region, and it has been widely used in several studies. Through this calculation, it is possible to stratify the risk for the development of cardiovascular diseases in individuals. In our study, a significant difference was found in comparison to the physical activity groups. It is possible to affirm that physical activity, when practiced according to the weekly recommendations, decreases the values of this relation due to the great demand of energetic substrates required during such activities [16]. The results obtained in the multivariate analysis showed that the regular practice of physical activity confers a protective factor regarding the development of LS (odds ratio $=0.34$ ); that is, individuals who regularly practice physical activities at moderate intensity and/or vigorously can obtain effects that promote good maintenance of the hepatic metabolism, besides the general improvement in the clinical picture.

Reinforcing this finding, Tsunoda et al. [20] demonstrated in their study that physical activity, mainly of vigorous intensity, has a positive effect to prevent hepatic steatosis and other liver diseases. This can be explained by the relation of the use of energetic substrates used during the practice of physical activities, which in turn activates the AMP kinase cycle [4]. Activation of AMP kinase increases the production of ATP, mainly through the oxidation of free fatty acids and glucose transport. In addition, the decrease of intrahepatic glycogen leads the liver to trigger higher consumption of fat, consequently decreasing this stock [4]. Decreased intrahepatic stocks lead the liver to extract energy substrates from other sites such as adipose tissue and/or blood circulation. With this, excess fat, located in the liver, is used to generate energy during and after the practice of physical activities by positively regulating the lipid profile and improving the clinical picture of patients affected by LS. More studies are needed to better understand the relationship between regular physical activity and parameters related to the clinical condition of patients with hepatic steatosis and its relation to hepatitis $\mathrm{C}$ virus infection.

\section{Conclusion}

It is concluded that the regular practice of physical activity generates a protective factor against the development of LS in patients infected by the hepatitis $\mathrm{C}$ virus. In addition, regular physical activity is associated with the maintenance of variables related to hepatic and biochemical damage, attenuating the clinical features of these patients. The study also represents a contribution regarding the clinical aspects of LS in Brazil, since the data on this frequent and important liver condition are limited.

Conflict of interest: Authors state no conflict of interest.

\section{References}

1. Adinolfi L.E., Gambardella M., Andreana A., Tripodi M.F., Utili R., Ruggiero G. (2001) Steatosis accelerates the progression of liver damage of chronic hepatitis $\mathrm{C}$ patients and correlates with specific HCV genotype and visceral obesity. Hepatol., 33(6): 1358-1364. DOI: 10.1053/jhep.2001.24432.

2. Blair S.N., Kampert J.B., Kohl H.W., Barlow C.E., Macera C.A., Paffenbarger R.S., Gibbons L.W. (1996) Influences of cardiorespiratory fitness and other precursors on cardiovascular disease and all-cause mortality in men and women. Jama, 276(3): 205-210. DOI: 10.1001/ jama.1996.03540030039029.

3. Chan A., Patel K., Naggie S. (2017) Genotype 3 Infection: The Last Stand of Hepatitis C Virus. Drugs, 77(2): 131-144. DOI: 10.1007/s40265-016-0685-x.

4. Chen Z.P., Stephens T.J., Murthy S., Canny B.J., Hargreaves M., Witters L.A., McConell G.K. (2003) Effect of exercise intensity on skeletal muscle AMPK signaling in humans. Diabetes, 52(9): 2205-2212. DOI: $10.2337 /$ diabetes.52.9.2205.

5. De Sousa S.M., Norman R.J. (2016) Metabolic syndrome, diet and exercise. Best Pract. Res. Clin. Obstet. Gynaecol., 37: 140-151. DOI: 10.1016/j.bpobgyn.2016.01.006.

6. Fraga A.S., Ladeia A.M.T., Sá C.K.C.D., Tenório M.C.C. (2017) Efeito do exercício sobre os níveis de hdl-c: uma revisão sistemática de metanálises. Revista Brasileira de Medicina do Esporte, 23(6): 488-494.

7. Franco L.D.P., Campos J.A.D.B., Demonte A. (2009) Dietary fat content, serum lipid levels and body weight of exercised rats. Revista de Nutrição, 22(3): 359-366.

8. Guedes D.P., Gonçalves L.A. (2007) Impacto da prática habitual de atividade física no perfil lipídico de adultos. Arq. Bras. Endocrinol. Metab, 51(1): 72-78.

9. Hannah W.N., Harrison S.A. (2016) Effect of weight loss, diet, exercise, and bariatric surgery on nonalcoholic fatty liver disease. Clin. Liver Dis., 20(2): 339-350. DOI: 10.1016/j.cld.2015.10.008.

10. Haskell W.L., Lee I.M., Pate R.R., Powell K.E., Blair S.N., Franklin B.A., Bauman A. (2007) Physical activity and public health: updated recommendation for adults from the American College of Sports Medicine and the 
American Heart Association. Circulation, 116(9): 1081. DOI: 10.1249/mss.0b013e3180616b27.

11. Lakka T.A., Laaksonen D.E., Lakka H.M., Männikkö N.I., Niskanen L.K., Rauramaa R., Salonen J.T. (2003) Sedentary lifestyle, poor cardiorespiratory fitness, and the metabolic syndrome. Med. Sci. Sports Exerc., 35(8): 12791286. DOI: 10.1249/01.MSS.0000079076.74931.9A.

12. Loomba R., Cortez-Pinto H. (2015) Exercise and improvement of NAFLD: Practical recommendations. $J$. Hepatol., 63(1): 10-12. DOI: 10.1016/j.hep.2015.03.009.

13. Matsudo S., Araújo T., Matsudo V., Andrade D., Andrade E., Oliveira L.C., Braggion G. (2012) Questionário Internacional De Atividade Física (Ipaq): Estupo De Validade E Reprodutibilidade No Brasil. Revista Brasileira de Atividade Física \& Saúde, 6(2): 5-18.

14. Monteiro C.A., Mondini L., De Souza A.L., Popkin B.M. (1995) The nutrition transition in Brazil. Eur. J. Clin. Nutr., 49(2): 105-113. PMID: 7743983.

15. Oliveira M.A.M., Fagundes R.L.M., Moreira E.A.M., de Moraes Trindade E.B.S., de Carvalho T. (2010) Relação de Indicadores Antropométricos com Fatores de Risco para Doença Cardiovascular. Arq. Bras. Cardiol., 94(4): 478-485.

16. Paffenbarger Jr. R.S., Lee I.M. (1996) Physical activity and fitness for health and longevity. Res. Q. Exerc. Sport, 67(sup3): S-11. DOI: 10.1080/02701367.1996.10608850.

17. Pettersson J., Hindorf U., Persson P., Bengtsson T., Malmqvist U., Werkström V., Ekelund M. (2008) Muscular exercise can cause highly pathological liver function tests in healthy men. Br. J. Clin. Pharmacol., 65(2): 253-259.

18. Shephard R.J., Johnson N. (2015) Effects of physical activity upon the liver. Eur. J. Appl. Physiol., 115(1): 1-46.

19. Smart N.A., King N., McFarlane J.R., Graham P.L., Dieberg G. (2016) Effect of exercise training on liver function in adults who are overweight or exhibit fatty liver disease: a systematic review and meta-analysis. $B r$. J. Sports Med. DOI: 10.1136/bjsports-2016-096197.

20. Soler G.L.N., Silva A.W.S.M., Silva V.C.G.D., Teixeira R.D.J. (2008) Doença hepática gordurosa não-alcoólica: associação com síndrome metabólica e fatores de risco cardiovascular. Rev. Socerj., 21(2): 94-100. DOI: 10.1016/j.ramb.2012.10.004.

21. Tsunoda K., Kai Y., Kitano N., Uchida K., Kuchiki T., Nagamatsu T. (2016) Impact of physical activity on nonalcoholic steatohepatitis in people with nonalcoholic simple fatty liver: A prospective cohort study. Preventive Medicine, 88: 237-240. DOI: 10.1016/j.ypmed.2016.04.020.

22. Padoin A.V., Staub H.L., Chatkin J.M., Moretto M., Maggioni L., Rizzolli J., Mottin C.C. (2008) Doença hepática não-alcoólica gordurosa e risco de cirrose. Scientia Medica, 18(4): 172-176.

23. Tiainen S., Luoto R., Ahotupa M., Raitanen J., Vasankari T. (2016) 6-mo aerobic exercise intervention enhances the lipid peroxide transport function of HDL. Free Radic. Res., 50(11): 1279-1285.

24. Yazbek M.A., Marques Neto J.F. (2008) Osteoporose e outras doenças osteometabólicas no idoso. Einstein, 6(sup 1): S74-S8.

25. Yki-Järvinen H. (2015) Pathogenesis of nonalcoholic fatty liver disease (NAFLD). International Textbook of Diabetes Mellitus, 2: 283. DOI: 10.1002/9781118387658. ch19.

\section{Received 23.01.2018 \\ Accepted 11.06.2018}

(C) University of Physical Education, Warsaw, Poland 